\title{
Don't Sell Tobacco to Dante: Scribbled Images of Tage Danielsson's Inferno
}

\author{
Alžbeta Jurkovičová
}

\begin{abstract}
Tage Danielsson's novel Mannen som slutade röka: en psykologisk thriller (The Man Who Quit Smoking: A Psychological Thriller) is a fictional diary of an executive director named Dante Alighieri. Riddled with various scribbles, doodles, and side comments, the work offers a wide range of possibilities for exploring the functions of these visual elements. This paper explores how the integrated text and pictorial expressions function within the context of the stylized diary, and on what scale it realizes the connection between the conventional word and the seemingly automatic, manic, cyclical scribbling and writing.
\end{abstract}

\section{Keywords}

media integration; scribble; doodle; fictional diary; self-referentiality 


\section{Introduction}

"Warning! Do not under any circumstances sell tobacco to this man! / The authorities." reads the text under a photo of despairing Dante Alighieri, who is thus turned away after he tries to buy a pack of cigarettes in the newsstand (Danielsson, 1972, 0:33:50). Just when he thinks that he has finally outwitted secret agents from the detective agency Little Secret Service, whose job it is to thwart his smoking attempts, Dante realizes that all the city's kiosks are most likely filled with identical warnings about his possible visit. Together with the utterly ambiguous signature "The Authorities", the photo of Dante is merely one of many absurd humorous elements in Tage Danielsson's film The Man Who Quit Smoking $(1972)^{1}$, in which transmediation and media representation play an important role. Not only is the story of the film, in intermedial terms, a double transmediation - as it is a film self-adaptation of Tage Danielssons's novel The Man Who Quit Smoking: A Psychological Thriller $(1968)^{2}$ that already transmediates elements from Dante's Divine Comedy ${ }^{3}$ but the novel itself offers a unique scope for exploring numerous intermedial relations.

The Man Who Quit Smoking: A Psychological Thriller (from now on The Man Who Quit Smoking) is a fictional diary of a man named Dante Alighieri, a director of a successful sausage-manufacturing empire, whose "inferno" revolves around his strenuous attempts to quit smoking. Stylized as diary entries with every spread consisting of a typewritten text on the right side and hand-drawn images and scribbles, created by Per $\AA$ hlin ${ }^{4}$, on the left side, it is exactly these text-image relations that are the starting point of this paper. There is an important point in looking at this work in intermedial perspective, as the text does not automatically have priority and instead, text entries and pictorial scribbles are integrated in various ways. It is, then, through this integration and close interplay, that the work can fully communicate, and the comedic elements emerge in their entirety.

Moreover, not only do the images communicate with the text entries through the diary form of the novel, but there is also an interesting tension stemming from the scribbling character of the left side of the spreads, that is worth exploring. Using the framework and intermedial terminology of Lars Elleström, and conception of the scribbling phenomenon presented by Christian Driesen in Über Kritzeln: Graphismen zwischen Schrift, Bild, Text und Zeichen, this paper aims to examine how the respective sides of the spread, both being part of the diegesis, communicate. Furthermore, I seek to explore how fluidity of scribbles and doodles can be described and what function they have in the narrative and the interpretation of the story.

\footnotetext{
1 Original Swedish title: Mannen som slutade röka.

2 Original Swedish title: Mannen som slutade röka: en psykologisk thriller.

3 Intertextual aspects of the novel are discussed in more detail in Conny Svensson's De läste Dante. Från Boccaccio till Tage Danielsson (2020).

4 Similar to the majority of his books, Tage Danielsson cooperated with the artist Per Åhlin, who illustrated Dante's diary (the novel), and he also made animations of his own illustrations in the film adaptation The Man Who Quit Smoking (1972).
} 


\section{Relations among texts and media}

When discussing relations among media, I use the framework of Lars Elleström, and his distinction between two main perspectives on theoretical studies on intermediality, which are a synchronic and a diachronic perspective (Elleström 2014: 3). To fully grasp these intermedial relations and the perspectives for their analysis, it is important to first understand Elleström's conception of media and media modalities. Based on the notion that "media are both different and similar, [...] intermediality must be understood as a bridge between medial differences that is founded on medial similarities" (Elleström 2021: 5). He defines four modalities of media: the material, the sensorial, the spatiotemporal, and the semiotic modality, which represent the essential transmedial basis of Elleström's framework, and are "the types of traits common for all media products" (2021: 46). The modes of the modalities, then, are "unions of particular traits belonging to the four modalities" (2014: 37-38) or, "the specific traits of particular media products or types of media products" 2021: 46).

Elleström distinguishes between basic media, qualified media, and technical media. Basic media are defined exclusively by their modal properties, as mentioned above. When characterizing qualified media, their cultural, social, historical, aesthetic, and communicative aspects are taken into consideration (2010: 5). Technical media of display, then, are physical entities that mediate or display basic and qualified media, they are the objects we need to realize media products and hence media types. Lastly, Elleström adds, when using the term medium without further specifications, it generally refers to all mentioned media aspects (2021: 9).

The synchronic perspective reveals how different basic and qualified media types can be understood, analysed, and compared in terms of the combination and integration of fundamental media traits. It involves considering how media features appear at a certain moment, (71-74) for example when texts and images communicate on the flat surface of a page. For Elleström is it important to emphasize the notion of combination and integration equally, as combining media properties always entails a certain degree of mutual integration (75). Since this article deals with specific kinds of pictorial expressions (on a scale from abstract scribbles to handmade drawings), it is important to note that Elleström mentions such delimitations. If we need to focus on a certain type of still image (he gives the example of children's drawings), we are talking about a qualified medium (2021: 55). In a similar way, we could surely demarcate other qualified types of media products. The qualified medium is "more fluid than the basic medium of still image simply because the added criteria are optional and more variable than those captured by the media modalities" (ibid.). Concerning drawings, Elleström points out the difficulty of agreeing on what a handmade drawing actually is; furthermore, he poses a question using an example relevant for this paper: "should drawings made on computers or scribble on the wall be included?" (ibid.). By this, he stresses how ambivalent and debated the limits of qualified media types are, in contrast to the basic media types' limits (ibid.).

The second perspective that Elleström distinguishes is the diachronic perspective. It shows how transfer and transformation of media characteristics are comprehended and 
described; and how these characteristics appear in relation to preceding (and possibly also subsequent) media (73-74). Elleström distinguishes between two fundamental types of media transformations: transmediation of media characteristics and media representation. ${ }^{5}$

\section{The scribbles in between}

From intermedial point of view, the scribbles and doodles present in the novel could thus be viewed on the level of basic media integration, as images strongly integrated with the text of the novel. Without decoding the letters and thus entering the symbolic interpretation yet, we can initially describe the spreads as a coexistence of different visual expressions on the flat surface of the page. The expressions differ in their physical production, the right side of the spread having been produced by a typewriter (mechanical production), and the left side being written/drawn/scribbled by a pen $^{6}$ and a hand (manual production); and in some cases, by alternating the two.

However, these pictorial expressions establish a place of "in-betweenness", that could be explored through their very nature that is their scribbling character. But what are these scribbles and how can they be described? In the introduction of the book Über Kritzeln, Christian Driesen, Rea Köppel, Benjamin Meyer-Krahmer and Eike Wittrock explain that the phenomenon of Kritzeln, that is scribble/scribbling in English, is usually described ex negativo, that is as non-writing, non-sign, non-image or non-text. It is important to add, however, that these scribbled lines cannot be grasped through their opposites; and they rather refer to what they just still are or just no longer are. The scribbles as a phenomenon thus actually point to the overlapping marginal areas of writing, image, sign, and text. The authors comment on the scribbles' "out of placeness" stemming from the attempts to define them from different sides; because they stand concurrently before writing and image (e.g. as still unformed attempts by children), after (as no longer legible scribble), next to it (as an autonomous work of art) and in between (as a hybrid of writing and drawing) (Driesen et al. 2012: 7). ${ }^{7}$ As the scholars in Über Kritzeln put it, the sharpness of the scribble's lines is contrasting with the vagueness of its terms, its seman-

5 The intermedial notions and perspectives of transmediation and media representation should be described in detail when exploring the diachronic perspective. In our particular case, it would be necessary for the analysis of the film adaptation, or further analysis of themes and images from Divine Comedy being mediated again by a different media product (the novel in question and the film adaptation). In its fundamental definition by Elleström, the process of transmediation is at work when "equivalent sensory configurations (sensory configurations with the capacity to trigger representations that correspond to those of a source medium) are mediated for a second (or third or fourth) time and by another type of technical medium” (Elleström 2014: 20).

6 or another writing/drawing toll.

7 "Kritzeleien werden meist ex negativo beschrieben - als Nicht-Schrift, Nicht-Zeichen, Nicht-Bild oder Nicht-Text. Über ihre Gegensätze lassen sie sich jedoch nicht erfassen, denn gekritzelte Linien sind nicht von einem Wesen her zu denken: Sie verweisen eher auf das, was sie gerade noch oder gerade nicht mehr sind; sie deuten auf die (sich überschneidenden) Randbezirke von Schrift, Bild, Zeichen und Text. Ihr Status ist insofern prekär, als durch die Bestimmungsversuche von verschiedenen Seiten her ihr Ort als ein atopischer sichtbar wird, denn sie stehen zugleich vor Schrift und Bild (als noch ungeformte Versuche von Kindern etwa), 
tics and taxonomy, so it is always clear and vague in one; and this kind of indeterminacy thus involves the possibility of diverse interpretations (ibid.). The aspect of transformation is crucial - when writing drifts into the image or vice versa, then both are neither the one nor the other at the moment of their transformation (ibid.). It is precisely this in-betweenness of the scribbles and doodles included in Dante's diary that pick our curiousness for further analysis. Although scribbles are, at least in Driesen's framework, associated with the emergence of undetermined forms, vagueness, aimlessness and dissemblance (Driesen n.d.), this is not the case of every pictorial expression resulting from scribbling behaviour. Rather, the starting point for this article is the view of the scribblings as transformative passages from writing into image and vice versa.

In his study "Kritzeleien im Sudelbuch. Zu Lichtenbergs Schreibverfahren”, Rüdiger Campe explores scribbles as a medium specific to Sudelbuch ${ }^{8}$. He explains that the connection between the two is based on "the unfulfillable creed of 'writing everything down', which leads to writing infested with scribbling" (Driesen et al. 2012: 13). And although Campe explores this intention of scribbles in relation to a specific genre, we could pose the question if the urge to write everything down, to keep one's hands busy, could be viewed as one of the characteristics of scribblings in general, regardless of literary genre.

When discussing and relying on the phenomenon of Kritzelei, it is also important to clarify the English terminology used in my article. Thus far, I have used the English terms scribble and doodle interchangeably. Driesen himself uses the term scribble when describing the phenomenon in occasional English texts. However, depending on the context, the two terms bring on different connotations and implications. Several scholars have distinguished between these two terms, others have used scribble and doodle rather synonymously. Matthew Battles differentiates between the two and he highlights the doodle as "at once the most common and the most ignored art form, [...] preliterate and primordial" (Battles 2004: 2). He describes scribbling, by contrast, as "hasteful marks made by an uncertain hand" (3). David Maclagan makes the distinction on a basis of the markings' relation to language. As he explains, "a scribble is, almost by definition, in some kind of collision with language, or at least with visual articulacy [...]. A doodle, on the other hand, nearly always has some connection with language, either because it is literally made in the margins of a manuscript or text, or because it can be 'read' as if it were some kind of unconscious writing" (Maclagan 2013: 22). Both scribble and doodle are clearly shifting categories. The idea of scribble and doodle being two different levels on the scale of conscious intent and concreteness, or that the one as an extension of the other, is supported by the following categorization made by Sunni Brown.

The key criterium for distinction being the degree of abstractness and the degree of spontaneity versus control, scribbles are understood as "random, abstract lines generally made without lifting the drawing tool", while doodles are "spontaneous [but more concrete] marks made to support thinking" (Brown 2015: 12-13).

danach (als nicht mehr lesbares Gekrakel), daneben (als autonomes Kunstwerk) und dazwischen (als Hybrid aus Schrift und Zeichnung)" (Driesen et al. 2012: 7).

8 Sudelbuch was originally synonymous with Kladde or Strazze, a merchant's language term for a book, in which one writes the first careless version of a text to be carefully copied later. (Wörterbuchnetz.se n.d.) 


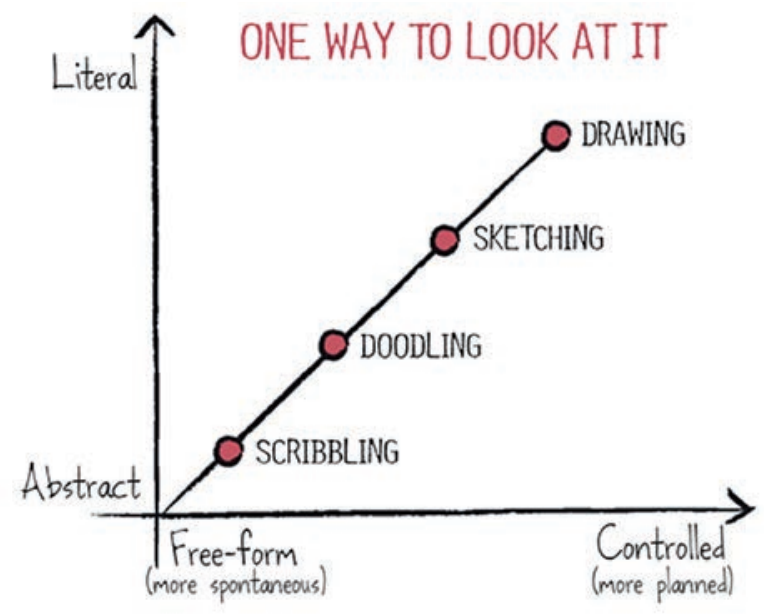

Figure 1. Sunni Brown's distinction of DOODLING VS. SCRIBBLING, SKETCHING, AND DRAWING.

Expanding on his distinction mentioned above, Maclagan elaborates not only on the connection between scribbles and doodles, but he also searches for the phenomena's connection to automatic drawing. He asks what factors are qualifying a drawing as being 'automatic'. On one hand, such drawing should be created in a state of dissociation or under compulsion, on the other hand, the style of drawing itself is "more or less fluid or gestural, and that seems to bear the evidence of spontaneity" (Maclagan 2013: 14). Besides the aspects of "abstractness" and spontaneity, he also talks about the levels of intentionality (22), something that is an inherent part of discussions about these phenomena, however, this aspect would be difficult to discuss in the context of the work of fiction analysed here. Maclagan sees scribblings and doodlings as unconscious expressions, by which he means that they are made in a distracted state or for other than an artistic purpose (12). Something that perhaps further differentiates doodles from artistic pictorial portrayals (on our scale: sketching and drawing), is the perceived escapist nature of doodling (19).

\section{Diary of a manic producer of signs: criteria for analysis}

The strong connections between Dante's text diary entries and his scribbles and doodles in The Man Who Quit Smoking, are rooted in the same (mutual) function that Rüdiger Campe mentions in his study of Sudelbuch, namely the need to "write everything down". To explore the relations between the pictorial expressions and their textual counterparts, we have to determine the criteria for describing the selected expressions' relations to the text, as well as the relationships within the expressions themselves. Stemming from the thesis that pictorial expressions present in The Man Who Quit Smoking are positioned somewhere on their own scale of in-betweenness, the criteria that we will be considered are: 
- visual/formal criteria (pictorial expressions being abstract vs. concrete in terms of form $\left.{ }^{9}\right)$, and

- degree of controlled vs. spontaneous activity.

\section{Two poles of Dante's diary}

The Man Who Quit Smoking is a peculiar case of a stylized novel. In its stylization, we can observe two extremes. On one hand, Dante's story is written as diary entries, it stylizes the thoughtlessness, immediacy, and automaticity that a diary has. A Glossary of Literary Terms defines diary as a "day-to-day record of the events in one's life, written for personal use and satisfaction" (2009: 26). Regarding fictive diaries (as is the case of The Man Who Quit Smoking), Peter Morton distinguishes between the pseudo-diary and the mock-diary. He elaborates on this categories by clarifying that in the pseudo-diary, "every attempt is made to present the fiction as a real diary, ostensibly written by the protagonist" and that "there is no 'gap' between the diarist-narrator and the reader" (Morton 2006). On the other hand, it is a conventional literary text, a diary novel, conforming to certain literary conventions. Since the scribbles and doodles, as well as their function being ascribed to the need to "keep one's hands busy", are happening on the mimetic level of imitating a real diary, it is the first extreme that is more in focus in this article. Scribbling is one of the tools used for the stylization of the mindlessness, automatization, and immediacy associated with the diary form, but it also crosses over into a broader, deeper, and more conventional encoding. The other pole points out the fact that the work is concurrently supposed to be read like a novel conforming to pertaining conventions.

\section{"It's just that I have to keep my fingers busy. Otherwise, I go crazy."}

When the secret agents are nowhere near him, Dante must try to occupy his tobacco-desiring hands with something else, namely writing down his story in the form of a diary with various drawings, scribbles, and small repetitive texts. He is, in other words, engaging the hands instead of the nervous mind. Danielsson's Dante is a manic writer, or rather a manic producer of signs - it doesn't matter whether they are verbal or

9 Elleström notes that although thinking in terms of form and content could be sometimes problematic, it is unavoidable. "In its most fundamental aspect, form is created from relations among entities in material or mental space, and because spatial thinking is vital for cognition in general, the notion of form is indispensable to any effort to describe and interpret media. Consequently, form is an essential general compound media characteristic that covers a complex web of more specific structures of all types of sensorial inputs and cognitive entities. One might say that form is the master trait of media - it is the most broad-ranging of all compound media characteristics. Thus, form includes a variety of structural relations, manifested sensorially in what can be seen, heard, or otherwise perceived, or as cognitive configurations. A range of notions exists that are derivations of or specific aspects of form: pattern, rhythm, balance, proportion, repetition, and contrast, to name only a few. Other compound media characteristics that are said to have a formal nature are style and perspective." (Elleström 2014: 42-43) 
pictorial, he is constantly trying to engage his mind and hands for the sake of avoiding his primary impulses. Behaviour stemming from the urge to keep his hands occupied is, in other words, one of the characteristics of the main character. Posing the thesis that the function of "keeping one's hands busy" is at work both in the pictorial and the textual expressions, and even, at various levels of strength, it is important to explore the scale on which the literary text realizes the connection between the conventionalized word and the seemingly automatic, manic drawing ${ }^{10}$ and writing.

Dante writes the whole diary with the intent to "just have something to do something with his hands" (Danielsson 1968). The scribbling behaviour resulting from this credo is further manifested not only in the contentual aspect (i.e. what he writes about) but also in terms of the entries' form. In the foreword of his diary, Dante admits to his urges and, as it becomes clear from the way he writes, he literally uses the typewriter as an outlet for his physical restlessness. He makes mistakes and types over them; he writes the same words and sentences repeatedly or subsequently does not even care if the characters he types form actual words.

My name is Dante Alighieri. The reason I have
written this story is not any literary bent, nor
any irresistible urge to communicate something essential
to my fellow people, nor any greater need to make
money - in short, none of the reasons for writing accepted in
literary history ıcan be applied to parte the thing is that I have
this that I am writing.
quit smoking, and then you have to have something to do with your
hands all the time, and in that case a typewriter is good, and that is why I am wri-
ting. By the way, it's all a lie from beginning to end.
It's just that I have to keep my fingers busy. Otherwise

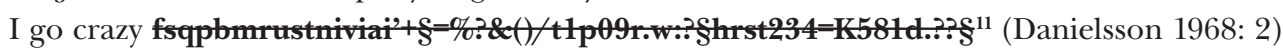

On the level of stylized automaticity, this "I have to write something, otherwise I go crazy" approach involves ultimately the same principle as the escapist and stress relieving processes that are happening while doodling. ${ }^{12}$ This is something that is very much in line with Dante's case of trying to "write, scribble and doodle himself out" of his ongoing

10 The word "drawing" is used here in the sense of describing "drawing activity" in general, not a drawing as a more controlled degree of a doodle.

11 "Mitt namn är Dante Alighieri. Anledningen till att jag har skrivit den här berättelsen är inte någon litterär ådra, inte heller någon oemotståndlig drift att meddela mina medmänniskor något väsentligt, inte heller något större behov av att skaffa pengar - kort sagt, inget av de i litteraturhistorien accepterade skälen till författarskap kan appliceras på plawääxxłemkom det här som jag skriver. fagskriver Utan det är så att jag har slutatröka, och då måste man ha någonstans att göra av händerna hela tiden, och då är ju en skrivmaskin bra, och därför författar jag. Alltihop är förresten lögn från början till slut. Det är bara det att jag måste hålla

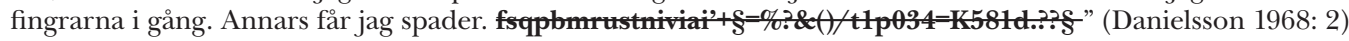

12 As psychological research suggests, doodling is, similarly to, for instance, fidgeting or pacing, used to alleviate mental stress in a "tense or restless state" (Maclay - Guttmann - Mayer-Gross: 1938). 
withdrawal hell; and it suggests that scribbling behaviour can be going on not only in the pictorial expressions of Dante's manuscript but also within the text entries themselves. However, the strongest effect of the scribbling phenomenon is perceivable in the already mentioned in-betweenness. Based on the thesis that the function of "keeping one's hands busy" is at work both in the pictorial and the textual expressions, the question is how do the various levels of the scribbled and doodled expressions work? In what ways do they relate to the text of the stylized diary?

The pictorial expression introduced below (Figure 2) demonstrates the overlapping marginal areas of writing, image, sign, and text that are associated with scribbles. The expression is only partially form-specific and in relation to referents that are thereupon ambiguous. The expression thus draws attention to its transformative character and these transitional passages between text (number) and image (merely an almost-likeness of a smoking figure) point out the spontaneousness of Dante's scribbling activity. The smoke-forming lines are hastefully scribbled over multiple times, making thus a connection between the pictorial cyclicity and the more abstract cyclicity of psychological mechanisms of the character's fidgeting behaviour. Still, on the mimetic level, the purpose of such an expression, made by a character in a diegetically introduced distracted state, is clearly non-artistic. Although the pictorial expression in question is abstract in terms of its formal and visual properties, we cannot say that it is non-referential. It contains signs alluding to the physical resemblance of creature-like figures, clouds, pipes, and cigars; and therefore, undoubtedly conveys messages. Considering the proposed scale of pictorial expressions and the chosen criteria, the example below positions itself at the first pole, i.e. the abstract and free-form end of the scale, based on the uncertainty, fluidity, and cyclicity of its lines. At the same time, we see reshaping transitions from conventionally coded numbers into uncoded freely scribbled lines of smoke, and vice versa. Furthermore, the transitional passages are not present only on the level of visual relations between text and image, but undeniably also in the realm of semiotics. The in-betweenness is rooted in the transitional passages between the symbolic, convention-based, coded language (alphanumeric symbols), and scribbled lines that are located somewhere in between their iconic (physical resemblance to the thing being represented) and indexical character. By understanding indexicality as representation based on contiguity between representamen and object (Elleström 2014: 13) ${ }^{13}$, i.e. something that shows evidence for the existence of what it refers to, we can see the pictorial expression as evidence of Dante's train of thought and desires, as well as a trace of him processing the events of his life (the number 17000000 shaped from dissolving smoke being the amount of money he is going to inherit in case of succeeding).

Furthermore, the reciprocal transition between conventional and non-conventional expressions can be explored not only within the left side of the spreads, but naturally also between the respective sides of the spread (the right side consisting of typewritten diary entries and the left side containing the scribbles and doodles). The range between something very conventionalized (the language of the text) on the one hand, and

13 Elleström follows Peirce's famous trichotomy of icon, index, and symbol. 
something quite abstract in terms of the convention (unclear and cyclical jotted lines in the margins) on the other, is quite rich. At the one end of the range of in-betweenness stand the pictorial expressions that have no contentual relation to the typewritten text.

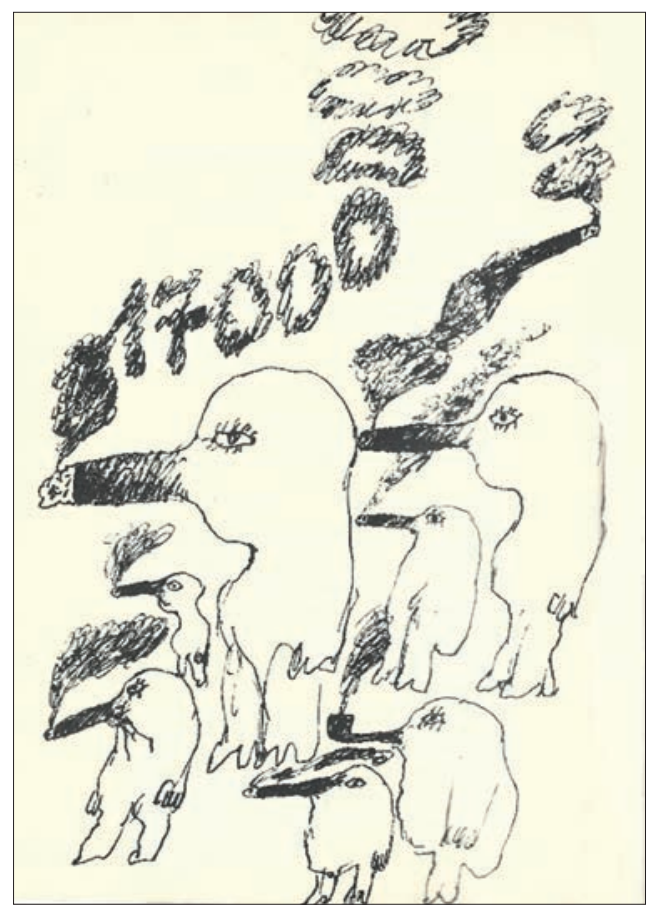

Figure 2. A pictorial expression from Dante's diary, Inferno, p. 23.

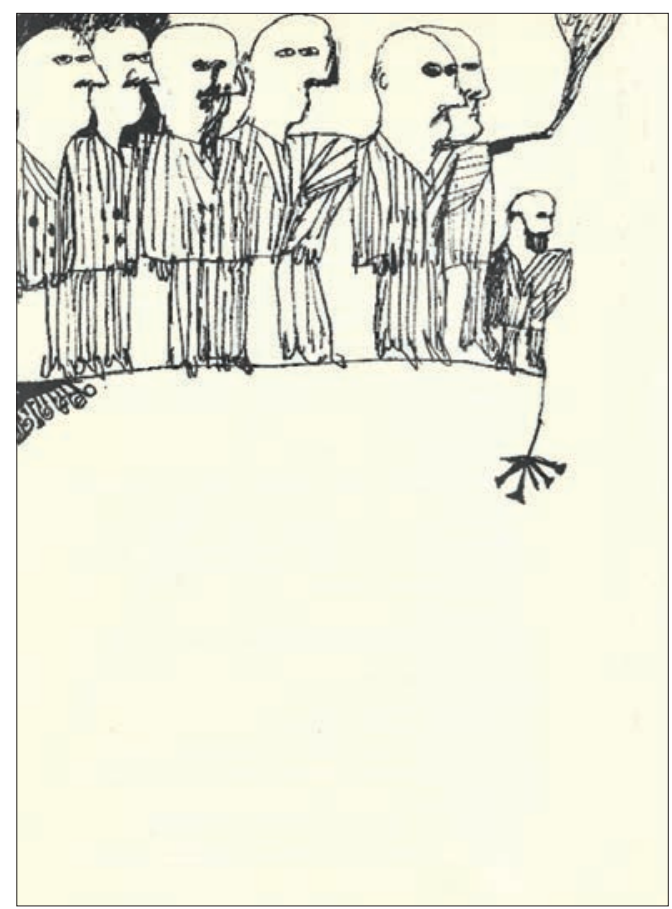

Figure 3. A pictorial expression from Dante's diary, Inferno, p. 28.

The idea of scribbles being traces of Dante processing his life's developments could be further extended when exploring spreads that are connected to the content of the text entries, i.e. the plot of the story. An exemplary instance of this is one of Dante's first encounters with the secret agents who are, ironically not very subtly, always all dressed in the same kind of cheviot suit. In his diary, he recounts a scene where the secret agents keep following him into shops and restaurants, pretending to be waiters and police officers. The frustrating recurrence of the agents appearing in his everyday life is, then, demonstrated in the corresponding pictorial expression on the same spread of the diary. The scribbled expression (Figure 3) depicts hastily scribbled figures in striped clothes, which implies that the connection between the text entry and the image is stronger than in the previous case, as the image is connected to the words (the text) in terms of content. However, although the expression is more controlled and concrete in terms of its visual properties, the scribbling character of the Kritzeln-phenomenon is demonstrated in the expression being crossed and scribbled over multiple times, as well as in the irreg- 
ular and repeated ornamentation at the edges. Moreover, the expression is seemingly made to look like it was created without lifting the drawing tool.

The reciprocal relation between text and image, communicating and carrying meaning together, is thus something very distinctive for the whole novel. At the same time, there is the central concept of manic writing (scribbling) that connects all the text-word integrations on all spreads and across the spreads. This central idea connects them beyond all the visual criteria. The two extremes are linked together by the function of keeping one's hands busy. One of the main ideas coming from the notion of seeing the integrated text-image relations as a scale is also the chance to demonstrate how dynamic and shifting these relationships are in terms of the elements' mutual illumination of each other's characteristics. In the first two examples, we can see that the pictorial element can illuminate both the unifying characteristic of the text and the work as a whole (Figure 2). What is expressed in one way in the text, is expressed in another form of sign relationship in the pictorial expression.

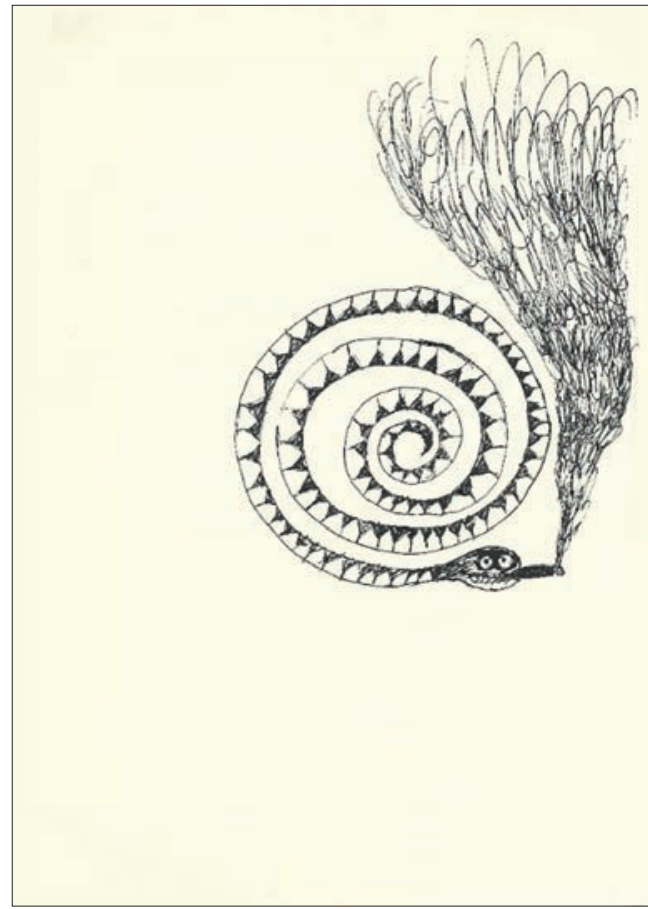

Figure 4. A pictorial expression from Dante's diary, Inferno, p. 56.

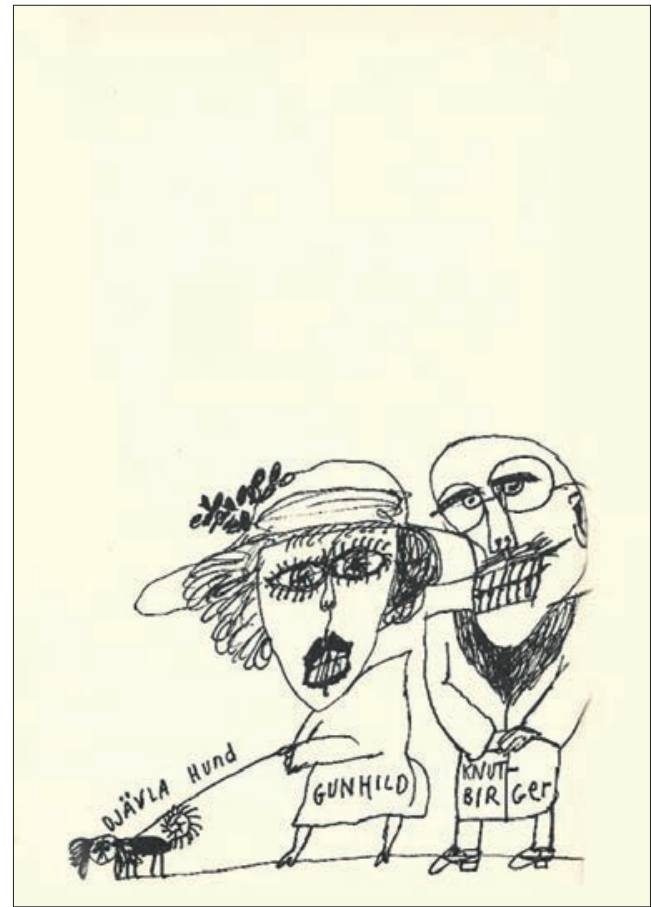

Figure 5. A pictorial expression from Dante's diary, Inferno, p. 56.

A good example of such instance is a diary entry describing various situations in which Dante repeatedly fights the temptation to pick up a cigarette. These allurements seem to haunt him, and it is only with the help of his beloved Beatrice Morris that he 
manages to resist. On one single spread, he recounts different situations and temptations that present themselves; it is a vicious cycle of smoking temptations. What the conventionalized text thus communicates, is the content - the circumstances, and solutions of these repetitive events. The pictorial expression (Figure 4) on the other hand, with its modal properties, expresses how the manic behaviour manifests itself spatially on the paper, with the repetitive, cyclical, crossed-out, scribbled lines, and filled-in patterns and geometrical shapes. The expression is clearly more formally specific, and the connection to the text entry is based on an indexical relation, as a trace of Dante's neurosis.

However, Dante's scribblings do not consist only of expressions that we at first glance interpret as pictures. We have previously encountered an expression (Figure 2) that contained scribbled lines forming an alphanumeric character. At another, a further level of our suggested scale, we come across cases in which words, i.e. symbolic language, are written within what we interpret as an image (Figure 5). Even if we do not know the meaning of these words, we automatically interpret them as something that is in relation to the doodled image (of two figures and an animal-like creature with four legs). There is, in other words, a proximity relation, indexicality in the composition itself. In terms of its visual style, the image is almost childishly scribbled, with its splay lines and bumpy shapes. They are, yet again, made to look like they were made without lifting the drawing tool (one of the characteristics of the scribble, according to Sunni Brown (2015: 17), although in this case, the lines are not random or abstract. They are fairly controlled in their form, or rather controlled to the extent of us being able to recognize what they are depicting. But it is only through the integration of the image and the text, that the reader can interpret the scene to the fullest. The image in question is connected to the typewritten entry in terms of the plot of the story, being integrated side by side with the text entry describing a meeting with Dante's uncle Karl-Birger and his mother's sister Gunhild at the law firm Sjöström, Sjöström, Sjöström, Sjöström \& Henning Sjöström, where Dante's father's last will is about to be read. The fictional Dante doodles things as he sees them, and since his intention with the diary is to tell the reader his story ${ }^{14}$, we can interpret this as him wanting to depict his surroundings and thought processes as well. ${ }^{15}$ This is also when the text integrated into the picture comes into play, serving as a caption for the respective pictorial parts, i.e. depiction of the two family members and the "damn dog" The presented image (Figure 5) thus once again points to the thesis that the scribbles and doodles present in the novel are oscillating between the convention-bound and the abstract, both in formal terms and in terms of various degrees of their communicative interplay with the text.

14 As previously mentioned in the Foreword (Danielsson 1968: 2).

15 This could be set in parallel to the first diary entry, from a day when Dante visits his dying father in the hospital, and he draws a very simple map of what the hospital looks like (e.g. where his father's bed is, where to find the nurse's room, and how to get out of the building (Danielsson 1968: 5). 


\section{Transition between text and image}

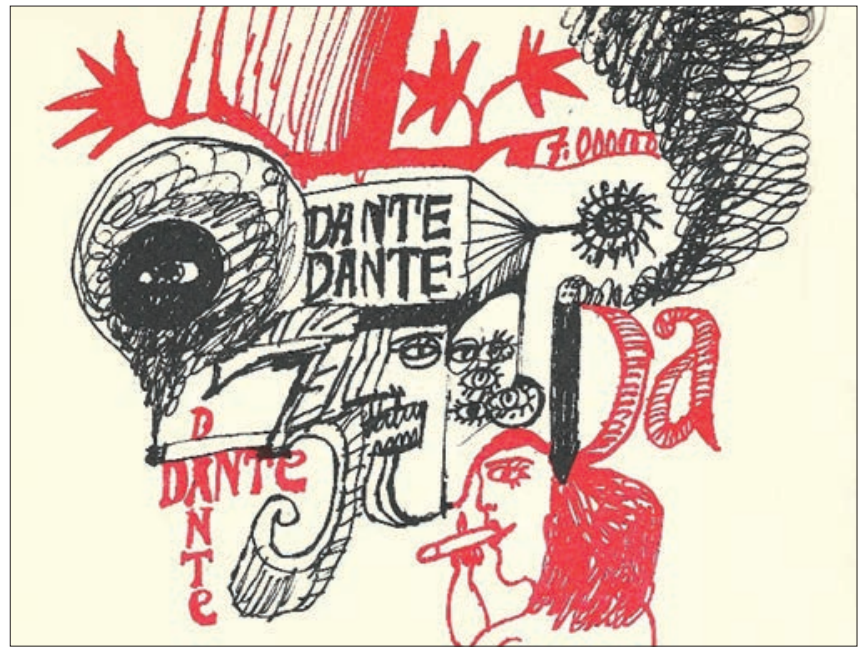

Figure 6. A pictorial expression from Dante's diary, Inferno, p. 17.

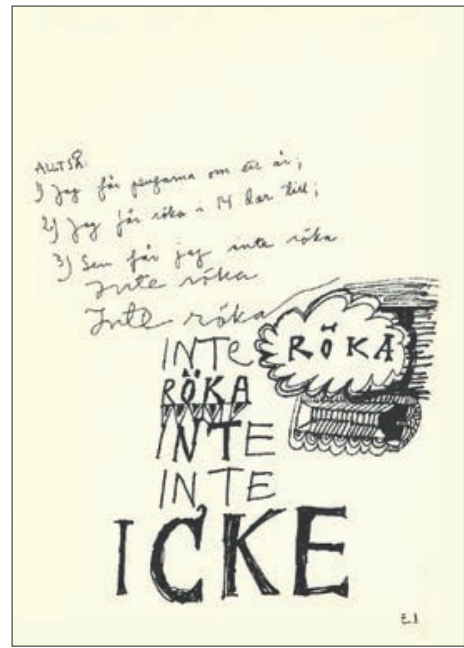

Figure 7. A pictorial expression from Dante's diary, Inferno, p. 8.

While the previous examples of text-image integration illuminated the fact that we need both media to communicate the story to its fullest potential, i.e. the importance of the media integration perspective itself, we must also point out other processes that are happening when encountering integrated scribbles and doodles. Expanding on our proposed scale, we are presented with expressions in which the continuity between text and image is very fluid, and they are proportionally more equally represented (Figure 6). This continuity is, as it was suggested earlier, given by the nature of the scribbles and doodles, and the corresponding effect of "keeping one's hands busy". All the previously mentioned elements are represented here, and the respective parts of the pictorial expression are continuously moving from complete abstraction, through spontaneous (but referential) circular scribbled lines, to a more controlled, concrete, and recognizable depiction, then through a text consisting of alphanumeric symbols, and back again. The textual elements are, of course, more conventionally coded than the pictorial abstractions, as they are symbolically referring to the character's name and the amount of money he so intensely thinks about. The parts of the expression that we interpret as pictorial, are visually more abstract (and less coded), but the connection to the conventionalized word is more pronounced, both visually - they are made to look like they are written without lifting the pen, but also in terms of the strong mutual connection to the function of "keeping one's hands busy". This multifaceted expression, a kind of image of the character's subconscious, represents yet another degree of the scale, and another demonstration of the transitional areas.

Furthermore, it is important to recognize the performance of the central idea "keep one's hands busy" happening across the spreads, i.e. relations between the contents of 
the right and the left side of the spreads. The intermedial relation in question (Figure 7) is a relation between the typewritten text and yet and yet another text, this time handwritten as a part of a scribbled expression. It can be described as the coexistence of verbal text produced with different technologies - manual and mechanical. Contextually, the handwritten text serves as a kind of a summarizing footnote, Dante's personal reminder and clarification of what his task is, namely, to stop smoking within 14 days and then to not, under any circumstances, smoke again. The character's need to repeatedly remind himself and reproduce his thoughts by writing them down, rehashing, and repeating certain words (“3., Then I can't smoke Don't smoke NOT SMOKE NOT SMOKE SMOKE NOT NOT NO" ${ }^{17}$ ) is connected to the leading idea of occupying his hands and finding an outlet for his fidgetiness. His constant writing "Jag ska inte röka" ("I will not smoke") is an indexical connection and a symptomatic expression of Dante's restlessness, we interpret these repetitions as a trace of something we can't see. The scribbling behaviour thus demonstrates itself both in terms of function, but also, partially, in the visual expression itself. The text has different sizes and fonts, some words are ornamented or flowing into scribbled lines and abstract depictions, creating (linking back to Driesen's categorization) yet another hybrid of writing and drawing. The presented expressions (Figure 6 and Figure 7) are clear examples of how writing and image flow into each other. It is a signal of them being in constant transition and a vice-versa-relation, and thus a confirmation of linking these expressions to the concept of scribbling.

\section{Transition between the two extremes: self-reference through the scribble}

We have previously ascribed the scribbling phenomenon to the first pole present in The Man Who Quit Smoking, and thus analysed its functions and effects within the mimetic level of the story. However, media integration of pictorial scribblings and typewritten text, as well as the effect of their reciprocal relation, go beyond the primary narrative line of the work, and we as readers encounter text references that imply self-referential elements being present. Drawing on Werner Wolf's conceptions of types of references in literature and media, I identify the self-referential elements as metareferences, proposing that media thematization is one of Danielsson's authorial strategies in this work. I follow up on Wolf's definition of metareference and its description by the following three distinctive traits:

17 Full translation: "SO:

1 , I get the money in a year;

2, I get to smoke for another 14 days;

3 , Then I can't smoke

Don't smoke

No smoking

NO SMOKING

SMOKING

NOT

NOT

NO” (Danielsson 1968: 8) 
(1) the existence of an intrasystemic reference (self-reference);

(2) the semantic quality of this intrasystemic reference; in other words: the fact that it consists of, or implies, a self-referential statement and is thus self-reflexive;

(3) a kind of medium awareness on the part of both producer and recipient which is implied or explicitly thematized in self-reflection and, thus, gives it a metadimension (this also implies the existence of a logical difference between the object level and the level of the metastatement). (Wolf 2007: 306-307)

Wolf continues by adding that the notion of metareference is primarily applicable to individual phenomena within certain works ("metaelements") (307). An example of such metaelement present in The Man Who Quit Smoking is the title page of the second part of the novel, called "Purgatorio".

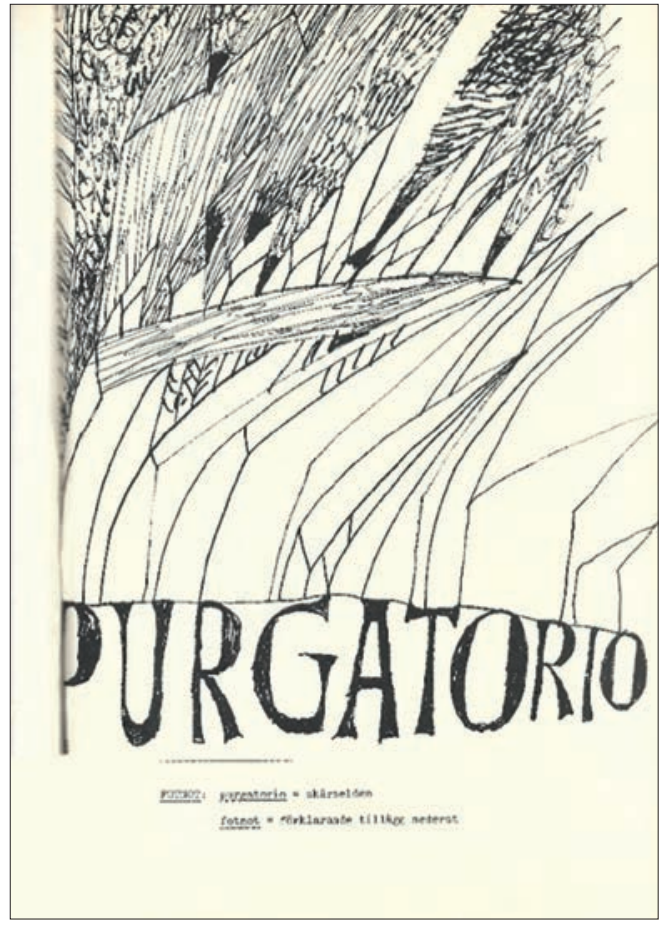

Figure 8. A title page of Purgatorio, the second part of Dante's diary, p.54.

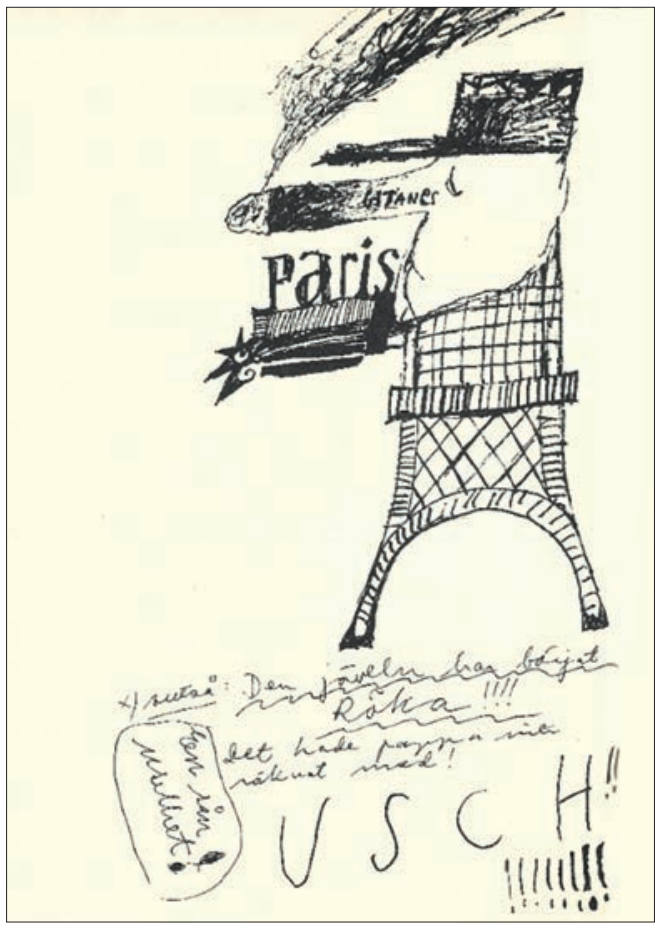

Figure 9. A pictorial expression with a footnote from Dante's diary, Inferno, p.35.

The title "Purgatorio" itself is hand-scribbled writing, connected to a pictorial expression, yet again, without any visual borders. The scribbled expression is abstract and not 
controlled in its form, consisting of sharp lines that are crossed-and scribbled-over multiple times; and thus, in line with both the overall function of "keeping one's hands busy", and Sunni Brown's classification of the scribble as "random, abstract lines generally made without lifting the drawing tool" (Brown 2015: 17). However, the spread with the section title also includes an element that is, by contrast, both controlled and conventionalized (a special kind of footnote that involves verbal language and punctuation $)^{18}$. A footnote, by definition, is a note of reference, explanation, or an additional comment, to which attention is drawn by means of a reference mark in the body of the text. It is usually placed below the text on a printed page, commenting on a specific part of the text on the page (Collins English Dictionary 2014). Here, however, we encounter a footnote that not only adds extra information about what is written on the page, but it also comments on itself and thus creates a kind of metalevel, and awareness of its own nature and function. This is the typewritten text below the scribble, i.e. the metaelement in question. It serves as a double footnote informing the reader (1) about the translation of the word "purgatorio" ("FOOTNOTE: purgatorio = purgatory" [Danielsson 1968: 2]); and (2) the meaning and function of a "footnote" ("footnote = explanatory note at the bottom" [ibid.]). I consider this double footnote to both imply a self-referential statement and to be self-reflexive in a way. It refers to the title of the book section, and thus reflects on the structure of the literary work being conventionally divided into chapters or parts, and it consequently reflects back on itself being a footnote explaining what a footnote is (self-reflectiveness). The relation to the literary work is thus not direct, it is rather chainlike: a picture is integrated with a text, a footnote is added to the text, and another footnote is added to refer to the first footnote, explaining how a footnote could be explained.

It is yet another outlet for the function of constant cyclicity that the work contains. It is a looped cycle of self-referentiality, correcting or commenting on itself, to the point of absurdity. Winfried Nöth talks about footnotes in the context of scholarly papers. However, I consider his understanding of this device as "indices used as metasigns in verbal texts" (Nöth 2009: 97) to be well-applicable here. As Nöth notes,

[t]he text of the footnote consists of symbols, but the mode of reference from the footnote number in the text to the corresponding footnote paragraph at the bottom of the page is an indexical metasign that directs the readers' attention not only from one point in the graphic space of the paper to another but also from one mental domain (of the author's primary arguments) to another (the one of the author's supplementary annotations). (Nöth 2009: 97)

Although the double footnote in Dante's diary does not include a footnote number, the referential direction of the readers' attention from one graphic space (the scribbled title page) to another (the typewritten footnotes), corresponds with Nöth's definition. The reader is thus pointed to the translation and the humorous self-reflective double-reference not through a numerical marker, but through a connection of being on the same page and, upon closer look, through adding more emphasis by having the crucial

18 The verbal language of the hand-scribbled text is naturally also convention-based, but the abstract pictorial scribble itself is not. 
words underlined. ${ }^{19}$ This doubled reference goes beyond the primary narrative line and comments (although through several steps) on the fact that Dante's diary is a work of fictional literature with a potential reader. The Man Who Quit Smoking thus differs from standard modernist novels (may it be genres such as diary or epistolary novel) by having someone who is not quite the same narrator commenting on what the primary diaristic narrator is writing. This metareferential device is a humorous one, amplifying both the comical and the self-referential aspect.

As a matter of fact, metareferential elements present in the novel can be observed as early as in the foreword to Dante's diary. Through the main character expressing the way his diary should be understood and analysed, Danielsson intrasystemicly comments on The Man Who Quit Smoking being read by a potential recipient as a coherent and conventional work. An essential part of Danielsson's author strategy is a constant movement between the two presented poles - the mimetic level and the level of literary conventions of the novel. Dante's foreword is a demonstration of Danielsson's authorial metareferential play, which he creates through different references to the text itself, as well as to the literary work as a whole. The entire foreword is stylized by the main character addressing the reader and objecting to the common reasons the reader could be interested in reading his diary. By entering a humorous dialogue with the reader, the author points to the reciprocal producer-recipient media awareness.

He alludes to the author-reader relationship, anticipating the reader's potential reception of the text ("The reason I have written this story is not any literary bent, nor any irresistible urge to communicate something essential to my fellow people" [Danielsson 1968: 2]). Furthermore, he reflects on the work potentially being subjected to the practice of literary history. Dante objects to the idea that his diary is being written with the intention to write a literary work. This self-reflective commentary creates a metadimension, in which an author of a diary novel (the object level) comments on the production process of creating a written work through a fictional character (the level of the metastatement). Although Dante does not address the readers directly, he inversely apologizes for the chaotic nature of his foreword; something that he, yet again, attributes to the compulsion to write for the sake of keeping his hands busy.

Using metareferences, the mimetic level, i.e., the character's story written and scribbled down in the diary, intertwines with the level of the conventionalized literary work and the level of Danielsson's authorial strategies. He takes his "winking at the reader" even further when he, on the stylized level of Dante's uncontrollable and cyclical scribbling behaviour, intentionally breaks the boundaries of the fictional world, and states that the author of the foreword is indeed not Dante: "[...] but all this is a lie and everyone who reads this knows that my name is not Dante Alighieri but what in the hell should you do when you have quit smoking" (ibid.). It is once again a play on self-referentiality; a witty allusion to fictionality, or rather to breaking the fictionality of the text and putting it back together with (1) the use of metaelements; and (2) the overarching allu-

19 Throughout the article, I briefly refer to the material aspects and different types of scripture of the respective scribbles and doodles. From intermedial and multimodal stand of point, this is a very interesting aspect worth exploring in future studies. 
sion to the function of "keeping one's hands busy". ${ }^{20}$

In the case of the double footnote (Figure 8), the metareference serves as a doubled explanatory commentary for the reader. This could be placed in comparison to the asterisks and footnotes that have an important function on the mimetic level of the story (Figure 9). Once again, Danielsson uses a whole range of unusual footnotes in Dante's diary. I have hitherto explored text-image integration and their mutual function. However, other layers occur when the reader is presented with Dante's thoughts and explanations that did not fit into the diary entries themselves, i.e. additions that Dante comes up with afterward. He marks them, as is common in texts, with an asterisk. Thus, two texts with different means of production are integrated and communicate together. They share all the four modalities, but the handwritten text (fulfilling the purpose of a footnote) cannot communicate to its full potential without the reader's understanding of the connection to the first typewritten text of the diary entry. Some of the spreads contain only handwritten text on their left side, other "footnotes" are made up of integrated text and scribbled image components that communicate jointly and together with the drawing. The example above (Figure 9) is implicitly connected to the plot through the function of "keeping one's hands busy“. Here, Dante tries to cope with his uncle trying to tempt him by taking up smoking himself: "*so: that jerk has started smoking!!!! Dad didn't expect that! UGH! such wretchedness!" (Danielsson 1968: 35). Furthermore, there are book spreads that contain the exact same text (with different production processes) on the respective sides, duplicated word for word. The fact that we get certain information duplicated or read two texts at the same time, is once again, a "confirmation" of the function of "keeping one's hands busy" being present in different forms, and the expressions resulting from this function being located on a multifaceted scale. Furthermore, we within the same text encounter a message that is partially from Dante to Dante (to cope and make sense of the situation), and at the same time, from Dante to the reader (explaining the implications of the events). Such addition of texts ("footnotes") at a later time, suggesting a return to the typewritten text of the diary entries, is one of the other cyclicities that are present in the work - it is thus not only about repetitions of words or patterns in pictorial expressions, but also a cyclical, time-returning commenting on what $\mathrm{I} /$ the character has already written.

\section{Conclusion}

As this paper explored, the text-image integration present in the novel The Man Who Quit Smoking: A Psychological Thriller is multifaceted and can be analysed through several

20 Danielsson takes the connection between "keep one's hands busy", creating contact with the reader, and expected media awareness on the part of the recipient even further. In the appendix of the book, he leaves small tasks and creative activities (e.g. a coloring page and a draw by numbers page) for all the potential recipients (readers) that, like Dante, want to quit smoking. This is, again, in parallel with the tasks that Dante leaves to himself on the respective pages of the diary, for example, a picture of an unsolved labyrinth with a smoking pipe in its center, which is also a metaphorical representation of the situation Dante is in. (Danielsson 1968: bilaga) 
different criteria. The connection between the respective elements has different degrees of strength on different spreads of the book, but it is only through their integration and close interplay that the literary work can communicate to its fullest potential. The paper examined Tage Danielsson's authorial strategies of stylization of a fictional literary text, with two poles being present, the first of which being the mimetic level strongly characterized by the function of "keeping one's hands busy". The urge to write everything down (on the mimetic level) has shown itself to be in close relation to repetitive, automatic, scribbling behaviour; which resulted in pictorial expressions functioning on different levels of "in-betweenness", both in terms of their (formal and conventional) character within themselves and in terms of their interconnection with the typewritten text. Furthermore, the "keep one's hands busy principle" is at work both in pictorial expressions and in the text, as well as in the mutual marginal areas. The interplay goes from conventional linguistic signs to completely unconventional abstract expressions that have no fixed cultural symbolism, and vice versa. Returning to the proposed scale of various degrees of pictorial expressions present in The Man Who Quit Smoking: A Psychological Thriller, it became clear that the scale is not straightforward. On the contrary, it is multifaceted, and the expressions move back and forth on the scale depending on their degree of formal concreteness, controlled activity, and the expressions' connection to verbal signs and conventionalized language. Finally, the integrated pictorial scribblings and texts connected to the function of "keeping one's hands busy" go beyond the primary narrative line of the work. They conduce to Danielsson's authorial metareferential play, forming references to the text itself, as well as to the literary work as a whole; and creating time-returning self-reflection.

\section{Sources and literature}

Abrams, M.H. \& Harpham, G.G. (2009). A glossary of literary terms. (9th ed.) Boston: Wadsworth Cengage Learning.

Bantleon, Katharina., Wolf, Werner, Bernhart, Walter. \& Thoss, Jeff. (2009). Metareference Across Media: Theory and Case Studies [electronic resource]. Editions Rodopi BV.

Battles, Matthew (2004). In Praise of Doodling. The American Scholar, 73(4), 105-108. http:// www.jstor.org/stable/41221340.

Brown, Sunni. (2015). The doodle revolution: unlock the power to think differently [electronic resource]. New York: Portfolio.Penguin.

Collins English Dictionary [electronic resource]. (12. rev. ed.) (2014). Glasgow: HarperCollins.

Danielsson, Tage (1968). Mannen som slutade röka: en psykisk thriller. Stockholm: Wahlström \& Widstrand.

Deutsches Wörterbuch von Jacob Grimm und Wilhelm Grimm. (n.d.). Sudelbuch. In Wörterbuchnetz.de dictionary. Retrieved July 25, 2021, from https://woerterbuchnetz.de/?sigle=DWB\&le$\operatorname{mid}=\mathrm{S} 55935 \# 0$

Driesen, Christian, Eike Wittrock, Benjamin Meyer-Krahmer, and Rea Köppel. (2012). Über Kritzeln: Graphismen zwischen Schrift, Bild, Text und Zeichen. Zürich: Diaphanes.

Driesen, Christian (n.d.). Ph.D. Project. Intensive signs - Expressive forms. On a theory of 
scribble as the difference between writing and image. Retrieved July 25, 2021, from https:// www.geisteswissenschaften.fu-berlin.de/en/v/schriftbildlichkeit/mitglieder/doktoranden/ driesen/index.html.

Elleström, Lars (ed.) (2021). Beyond Media Borders, Volume 1 [electronic resource] Intermedial Relations among Multimodal Media. 1st edition Cham: Springer International Publishing.

Elleström, Lars (2019). Transmedial Narration [electronic resource]. Springer International Publishing

Elleström, Lars (2014). Media transformation [electronic resource] the transfer of media characteristics among media. Basingstoke: Palgrave Macmillan.

Elleström, Lars (ed.) (2010). Media borders, multimodality and intermediality [electronic resource]. Basingstoke: Palgrave Macmillan.

Maclagan, David (2013). Line Let Loose: Scribbling, Doodling and Automatic Drawing [electronic resource]. Reaktion Books Ltd.

Maclay, W. S.; Guttmann, E.; Mayer-Gross, W. (1938). "Spontaneous Drawings as an Approach to some Problems of Psychopathology: (Section of Psychiatry)". Proceedings of the Royal Society of Medicine. 31 (11): 1337-1350.

Mannen som slutade röka [electronic resource] / directed by Tage Danielsson. - SF, 1972.

Morton, Peter (2006). "Narrative Strategies in the Fictive Diary.” Life Writing Symposium, 13-15 June 2006. Flinders: Flinders UP. Retrieved November 7, 2021.

Nöth, Winfried (2009). Metareference from a Semiotic Perspective. In Metareference Across Media: Theory and Case Studies [electronic resource], ed. Werner Wolf, Katharina Bantleon \& Jeff Thoss. Amsterdam - New York: Editions Rodopi BV

Sudelbuch. In: Jacob Grimm, Wilhelm Grimm: German dictionary. Hirzel, Leipzig 1854-1961 (woerterbuchnetz.de, University of Trier).

Wolf, Werner (2007). Metafiction and metamusic: Exploring the limits of metareference. In Self-reference in the media, ed. W. Nöth and N. Bishara. Berlin: Walter de Gruyter.

Mgr. Alžbeta Jurkovičová / ajurkovicova@mail.muni.cz

Masarykova univerzita, Filozofická fakulta, Ústav germanistiky, nordistiky a nederlandistiky Arna Nováka 1, 60200 Brno, CZ 